\title{
Career Strategies of Millennial Generation Female Assistant Coaches
}

\author{
Erin Morris \\ University of Illinois
}

\author{
Skye Arthur-Banning \\ Clemson University
}

\author{
Jacqueline McDowell \\ George Mason University
}

\begin{abstract}
The rate of collegiate female coaches is at an all-time low; but there has been limited research on what might help female coaches succeed. The millennial generation, who grew up with increased athletic opportunities provided by Title IX, is entering the profession, and they may have different views of coaching and athletics than previous generations. The purpose of this study was to investigate what factors influenced millennial generation, female assistant coaches' aspirations to become head coaches and what strategies they believed would help them successfully navigate their careers. The authors interviewed 10 millennial generation, Division I female assistant coaches and found leadership as athletes, appropriate education, and coaching networks, particularly with female coaches, were common strategies for feeling confident in their careers. These findings may help athletic departments create tools, such as women's only coaching clinics, to help encourage women to become and remain coaches and provide them with the required support.
\end{abstract}

Title IX of the Education Amendment Acts of 1972 (Title IX) states that "No person in the United States shall, on the basis of sex, be excluded from participation in, be denied the benefits of, or be subjected to discrimination under any education program or activity receiving Federal financial assistance" (20 U.S.C. \$1681). This legislation has played a significant role in increasing the number of women participating in sports; but Title IX inadvertently resulted in the rate of female head coaches plummeting. Specifically, in 1972, over 90\% of women's teams were coached by women, but currently this rate is at an all-time low of $43 \%$ (Acosta \& Carpenter, 2012). Unfortunately, this means that while exponentially more girls and women are participating in sport than they were in 1972, most do not have female coaches to learn from and relate to at the elite levels of sport. Anecdotal and research evidence has reinforced the importance of female coaches as role

Morris is with the Department of Recreation, Sport, and Tourism, University of Illinois, Champaign, IL. Arthur-Banning is with the Department of Parks, Recreation, and Tourism Management, Clemson University, Clemson, SC. McDowell is with the Division of Sport, Recreation, and Tourism, George Mason University, Fairfax, VA. Address author correspondence to Erin Morris at elmorri2@illinois.edu. 
models and mentors for women in sport. Female coaches serve to show female players that coaching is, in fact, an obtainable profession, and female players with female coaches are more likely to perceive coaching as a viable career option to them than those with male head coaches (Everhart \& Chelladurai, 1998; Lirgg, DiBrezzo, \& Smith, 1994).

There is now an entire generation-the millennial generation-that has experienced the benefits of Title IX in terms of participation and is now at the age where they could be head coaches. The millennial generation, defined as people born after 1980 (Taylor \& Keeter, 2010), are second generation Title IX beneficiaries who were exposed to more women participating in elite levels of sport and were raised in environments that were generally more accepting of women in sport. Millennial females had opportunities to play sport at far greater rates than any previous generation of women. They were also exposed to more female role models in sport as they were teen and preteens when the US Women's Soccer Team won the World Cup in 1999 and when the Women's National Basketball Association (WNBA) was formed in 1996. Moreover, millennials are less likely to be married or have children than previous generations at comparable ages and they tend to be more open to change and accepting of diversity than previous generations (Taylor \& Keeter, 2010).

One of the strongest influences on current perceptions and expectations of situations is past experience. Past experiences lead people to develop certain perceptions and expectations which they carry with them to work in organizations (Johns \& Saks, 2004). Millennial generation women did not face the same barriers to playing sports as women from previous generations did. There are significant differences in cultural experiences, both in the ability to play sports as well as the openness of many careers to women that may cause millennial women to perceive the coaching field differently from previous generations of female coaches. As such, their past experience with limited barriers in athletics may cause them to perceive fewer barriers to coaching than women who experienced more barriers while playing.

Previous researchers have examined barriers that limit women's upward coaching mobility and factors that influence women's decisions to be coaches or to leave the profession. This research sheds light on how the field is changing and why it is necessary to understand the experiences and perceptions of millennial women. When Lowry and Lovett (1997) looked at the different time periods when women left the coaching profession, they found that women were more likely to cite "heavy work load" immediately after Title IX was passed than in the two more recent time periods. While women do still cite time and work -life balance as barriers (Bracken, 2009), they may be less prevalent now due to changing social expectations around house-hold division of labor. Mainly, men are now spending more time doing household labor and childcare, and while women have not decreased their child care time, they are finding ways to decrease their time spent on household chores as they increase their time in the paid labor force (Bianchi, Robinson, \& Milkie, 2006). Thus, millennials may have different expectations and perceptions of work-life balance and their approach to the work force than previous generations. Lowry and Lovett (1997) also found that women were more likely to cite the lack of a supportive "old girls" club" as a reason for leaving sport post Title IX than women in previous generations. In recent decades, more efforts (e.g., Women Coaches Academy and the Alliance of Women Coaches) have been 
made to support female coaches; hence, it is important to see if these endeavors are actually helping the current generation feel more supported.

Based on millennial women's increased opportunities to participate in sports than previous generations, they may perceive more opportunities in the coaching field even though they likely did not have female coaches as role models. Their experience as athletes with more access to sport than women before them and more access to female athlete role models may make a difference in their perception of the coaching field. There is little attention, however, paid to generational differences and perspectives of the coaching profession. The limited work focusing on strategies that female coaches use to succeed tends to concentrate primarily on the usefulness of mentoring (e.g., Avery, Tonidandel, \& Phillips, 2008; Bloom, DurandBush, Schinke, \& Salmela, 1998; Weiss, Barber, Sisley, \& Ebbeck, 1991). This results in an incomplete understanding of the strategies used by female coaches. Furthermore, due to the limited research on women's head coaching aspirations and success strategies for navigating male dominated profession, hearing from millennial women about what they believe to be important factors in regards to what helps them stay in coaching is a necessary step toward increasing women's representation in collegiate head coaching positions. Given their differential sport experiences and perceptions, compared with previous generations, it is important to hear the perspectives of female coaches themselves in regards to the diverse strategies they view as useful in their own career advancement and success in a coaching career. As such, using a feminist standpoint perspective, the purpose of this study was to investigate what factors influenced millennial generation, female assistant coaches' aspirations to become head coaches and what strategies they believed would help them successfully navigate their careers.

\section{Literature Review}

As noted, women face many barriers in pursuing coaching careers, including salary, lack of opportunities (Weiss \& Stevens, 1993), the old boys' club, the lack of an old girls' club, gendered organizations (Claringbould \& Knoppers, 2008; Kamphoff, 2010; Stangl \& Kane, 1991), family and time commitment (Dixon \& Bruening, 2007; Kamphoff, 2010; Pastore, 1991; Weiss \& Stevens, 1993), lack of mentors, burnout, and administrators' perceptions of a lack of qualified female candidates (Everhart \& Chelladurai, 1998). Many of the barriers to women are influenced by the gendered nature of athletics and society as a whole. For instance, time and family commitment are some of the most commonly cited barriers, and while not all female coaches are married, partnered or have children, those that do often cite family obligations as a major barrier (Bracken, 2009; Dixon \& Bruening, 2007). This may be due to the societal expectations that women still bear a greater amount of the unpaid household labor-even while the gender gap is shrinking (Bianchi et al., 2006; Johnson \& Johnson, 2008).

Male dominated athletic director positions also create a gender bias in the hiring of coaches. Specifically, in 2011-2012, 80\% of athletic directors in 2012 were male; and as the level of competition increases, fewer women hold this prestigious position (Acosta \& Carpenter, 2012); that rate increases to $90 \%$ at Division I level and 95\% at the Football Bowl Subdivision, the most competitive level. Research has shown that on average approximately nine percent fewer female coaches are hired 
in Division I programs with male athletic directors than those with female athletic directors (Drago et al., 2005; Welch \& Sigelman, 2007), as administrators tend to hire those who are similar to themselves, leading to homologous reproduction within athletic departments (Sagas, Cunningham, \& Teed, 2006; Stangl \& Kane, 1991). For example, Sagas et al. (2006) found that the sex of a head coach significantly impacted the hiring of assistant coaches for women's teams and female head coaches were more likely to hire female assistant coaches. However, only $40 \%$ of male head coaches hired a male assistant coach when only one assistant was hired. The authors stated that male head coaches hiring female assistant coaches may be attributed to the idea that they need a female assistant to relate to the female players. Similarly, they state that women may be hiring other women in a conscious effort to increase women in coaching (Sagas et al., 2006).

While homologous reproduction may happen to varying levels within athletic hiring, the sparse number of women in the field may result in an environment that is not conducive to retaining the women that are hired. Athletic departments as a whole tend to be skewed ( 85 men: 15 women) or tilted ( 65 men: 35 women) organizations (Kane \& Stangl, 1991) as females hold between 20 and $36 \%$ of athletic administration and coaching positions (Acosta \& Carpenter, 2012). In skewed organizations, those in the minority are considered tokens and contend with pressures to conform to the norms of the majority to be accepted. When perceived as tokens, members of the minority group are less likely to stay in the organization (Claringbould \& Knoppers, 2008; Kane \& Stangl, 1991). Accordingly, the position of female coaches as tokens in sport organizations could possibly contribute to their low rate of participation in the field (Claringbould \& Knoppers, 2008; Kane \& Stangl, 1991).

\section{Factors Influencing Intent to Coach}

While barriers exist to limit women's entry and advancement in the coaching field, several facilitate women's upward mobility into head coaching positions. Time spent as an assistant coach, mentorship opportunities, and self-efficacy have all been found to positively influence women's intent to coach (Borland \& Bruening, 2010; Cunningham, Doherty, \& Gregg, 2007; Everhart \& Chelladurai, 1998; Sagas, Cunningham, \& Pastore, 2006). Sagas et al. (2006) suggested that women may have lower aspirations than men to become a head coach. They attributed this disparity to the experience these women had as assistant coaches and their interactions with their head coaches. Similarly, Cunningham et al. (2007) found that relative to female assistant coaches, male assistant coaches were more likely to have head coaching intentions, and greater head coaching self-efficacy. However, contrary to expectations, no gender differences were found in terms of support and barrier experiences.

Female coaches' decisions to enter the field of coaching are also influenced by a desire to stay involved in athletics, train high level athletes, be a role model, and help female athletes improve (Bower, 2010; Pastore, 1991). Many women believe that it is important for them to give back to the sport that has given them so much in life and to help the new generation of female athletes succeed. They enjoy assisting their athletes, whether that is by helping them become better athletes, or helping them get through a personal problem (Bower, 2010; Pastore, 1991). Assistant coaches are able to maintain this relationship as they are seen as 
the intermediaries between the coaching and the student-athlete worlds. While they serve as role models to the athletes, they also look up the ladder for their own support and progress. As role models, coaches can help facilitate an athlete's transition from player to coach. The presence of a female head coach provides a role model to show female athletes that coaching is a career possibility for them (Lirgg et al., 1994; Everhart \& Chelladurai, 1998). For example, Lirgg et al. (1994) found that high school girls with a female head coach were more likely to want to become a head coach; whereas girls with male coaches saw an assistant coaching position as desirable and more attainable rather than a head coaching position.

In addition to mentoring players to become future coaches, it is also important for coaches to have mentors themselves. Coaches seek out support, both from within their own department and from other coaches and organizations (Borland \& Bruening, 2010). More experienced coaches serve as mentors to help new coaches develop their own styles, navigate the gendered social space of coaching and reach their full potential (Avery et al., 2008; Bloom et al., 1998), and some organizations have started mentoring programs targeting female coaches, including the Women's Basketball Coaches Association "So You Want to be a Coach" Program and the National Collegiate Athletic Association (NCAA) Women's Coaches Academy. All mentoring connections are important and have utility, but the more similar the coaches are to one another, the stronger the tie and the more the coaches can learn from one another (Avery et al., 2008; Granovetter, 1973). Strong ties are especially important for women and minorities in gaining instrumental value, or the exchange of job-related resources (Ibarra, 1993; Seibert, Kraimer, \& Liden, 2001), and same sex mentoring allows for more career development than cross sex mentoring. Avery et al. (2008) support this, as female coaches in their study reported better psychosocial mentoring outcomes with same sex pairing than with opposite-sex pairings. Regardless of gender, mentors can help female coaches improve their career development and coaching abilities.

While time as an assistant coach and mentoring relationships can help women in coaching, their playing experiences also may influence their career intentions. Coaching self-efficacy is "defined as one's confidence in his or her capacity to perform the coaching tasks effectively" (Everhart \& Chelladurai, 1998, p. 191). Coaching self-efficacy influences coaches' assessment of their current situation, but also whether they think they will be successful at a higher level of coaching. Investigations of coaching self-efficacy have repeatedly found gender differences in that women tend to have lower coaching self-efficacy than men (Cunningham, Sagas \& Ashley, 2003; Marback et al., 2005). Specifically, this research suggests that players, who make up the pool of future coaches, are more likely to believe that they can succeed as coaches if they were competent athletes in their sport (Everhart \& Chelladurai, 1998). In accordance, Sagas et al. (2006) found that playing experience significantly influenced the self-efficacy of men and women athletes; however, education was also important for women. Women who believed that they had sufficient coaching education, or intended to receive more education in the next three years, had higher coaching self-efficacy and were more likely to pursue a head coaching position than those without sufficient education.

Beyond offering more education and networking opportunities, female coaches have commented on the necessity of having a flexible and supportive organization to feel accepted and to succeed in their careers (Borland \& Bruening, 2010; Drago 
et al., 2005). To help coaches balance family and childcare obligations with their demanding careers, some athletic departments have become more family friendly. These departments tend to allow more flexible time in the office, support having children at work, and have employees and administrators who work together to ensure that the coaches have the support and resources needed to balance their work and family life.

\section{Theoretical Framework}

As highlighted in the literature, many factors, such as mentorship, playing experience, and coaching education, influence women's career decisions in coaching (Avery et al., 2008; Bloom et al., 1998; Borland \& Bruening, 2010; Cunningham et al., 2003; Drago et al., 2005; Everhart \& Chelladurai, 1998). Since women are significantly underrepresented in coaching, they likely experience different barriers and use different strategies than men to succeed. As such, it is important for female coaches to discuss, in depth, the factors that impact them and their career trajectories from their own perspectives and lived experiences. To do so, we used feminist standpoint theory to investigate why millennial generation, female, assistant coaches pursued careers as head coaches and to delineate the perceived strategies that help them to achieve their career goals.

Feminist standpoint theory is grounded in feminist methods that give a voice to women's experiences in a male dominated world (Harding, 1987). Standpoint theory is a post-Marxian critical theory that regards ideology and institutional critique as crucial to the knowledge and liberation of women (Hartsock, 2004). It is based on the understanding that people will have different experiences in society based on their social standing in relation to their position of privilege. Thus, in phallocratic work environments, women will experience the labor force in different, possibly "othered" ways from men, especially in highly gendered career fields (Hartsock, 2004). Feminist standpoint theory centrally locates women's experiences so as to allow them to provide their unique views on society and culture. It acknowledges the multiple truths that exist based on one's social status, such as one's race, socioeconomic status, or job, and seeks to understand the lived experiences of women who are marginalized by social situations (Krane, 2001).

As collegiate coaching continues to be a heavily masculine field, several researchers have called for an increased use of feminist perspectives in sport research (Aitchison, 2005; Krane, 2001; Shaw and Frisby, 2006). There is a need to critically examine how the sport industry functions to understand why women have limited coaching opportunities available to them (Hartsock, 2004). For instance, Aitchison (2005) called for a more critical feminist perspective to analyze gender and power relations that take into account the structural and cultural nature of power in sport organizations. Meanwhile, Krane (2001) integrated feminist standpoint, queer theory, and feminist cultural studies to develop a lesbian feminist epistemology that highlights the differential experiences that lesbian athletes face in light of normative heterosexism in sport. Shaw and Frisby (2006) looked at the limitations of dominant liberal feminist frameworks used to investigate gender equity (i.e., fix the women, value the feminine, and create 
equal opportunities), and asserted that these frameworks are limited as they do not critically address the underlying systemic social and structural causes of gender inequities. Hence they advanced a fourth frame, based on poststructural feminism, that encourages individual and group awareness and self-reflection of sociopsychological processes that create gender inequities in sport organizations. Despite the asserted limitations of liberal feminist frameworks in sport management research, this study chose to use a liberal feminist framework as it did not seek to significantly alter the functioning of athletic departments or recommend one specific frame. Rather it sought to ascertain how current female assistant coaches experienced the field and what strategies they believe will be useful to them within the current system. The goal was not to radically alter the state of sport management, nor was there a belief that a small group of young assistant coaches could radically alter the athletic department.

\section{Methods}

For this study, qualitative interviews were conducted with Division I, millennial generation, female assistant coaches during the winter of 2011-2012 to discover information regarding the factors that helped the participants pursue their careers as coaches. Specifically, an instrumental case study design was used to critically analyze the assistant coaches' experiences and further the knowledge of what is necessary to succeed in their careers. Instrumental case studies seek to understand an issue or theory through the use of a particular case (Stake, 1995). The uniqueness of the case is less important than its ability to address the phenomena being studied or the relationships within it. As an instrumental case study, the interest in the phenomenon goes beyond the case itself to focus on the applicability of the career strategies in helping other coaches.

\section{Participants}

The participants were ten NCAA Division I female assistant coaches of women's teams. To maintain consistency of the size and type of athletic department, coaches were only selected from Division I Football Bowl Subdivision (FBS) schools. The coaches were all from the millennial generation (born after 1980), and all ten participants played intercollegiate varsity athletics for four years in the sport that they are currently coaching. One participant was an assistant coach for basketball, 5 participants were assistant rowing coaches, and 4 were assistant soccer coaches. The participants ranged in age from 23-31 years old. They had varying degrees of experience as assistant coaches at the collegiate level from one to nine years with an average of five years. None of the participants had been collegiate head coaches as the focus of the study was on assistant coaches and their perceptions of their ability to become head coaches. The participants all received bachelor's degrees, five participants held master's degrees and one participant was currently enrolled in a master's degree program. Participants were not asked to identify their race or marital status; however, based on the athletic department website biographies, two of the assistant coaches appeared to be African American, and during the interviews, three of the coaches said they were married or engaged. 


\section{Procedure}

Institutional Review Board approval was granted for this study. This study used purposive sampling to find participants. Athletic department websites of universities in the Southeast region of the United States were used to identify potential coaches for the initial interviews. The researcher used information from the coach biographies, such as college graduation years, on the university websites to determine if the coach was from the millennial generation. All coaches were asked at the end of the interview for recommendations of other assistant coaches who they knew that might be willing to participate. The researcher then used athletic department websites to check that the recommended assistant coaches fit all the necessary demographic categories before contacting them. All coaches were contacted via e-mail to set up the interview.

The primary researcher, a millennial generation woman, conducted all of the interviews. The interviews were digitally recorded, with the consent of the participants, and transcribed verbatim by the primary researcher. Two of the interviews were conducted in person while the other eight were conducted over the telephone. The interviews lasted from $25-70 \mathrm{~min}$. The primary researcher took notes concerning the important points, emerging research ideas, as well as emergent commonalities and differences among the interview at the conclusion of each interview. This aided the researcher's ability to compare main ideas in each interview and to keep track of repeated concepts during the data collection process (Creswell, 2007). To maintain confidentiality of the participants, they were assigned pseudonyms and all other identifying characters, such as a university name or the name of another coach, were dropped.

\section{Interview Guide}

The interviews were semistructured in nature and the questions were guided by previous literature on barriers and strategies to women in coaching. Sample questions included: what strategies and opportunities are helping you as an assistant coach to be successful? What would help you in pursuing a career as a head coach? What do you think makes a person qualified to become a head coach? The flow of the interview was adapted from Seidman's (2006) three part interview format: focused life history, the details of the experience, and reflections on the meaning of experiences. Hence the first part of the interviews focused on the participants' experiences as high school and college athletes. The second section inquired about their experiences and intentions to pursue a coaching career. The interviews concluded with questions aimed at eliciting the meanings they find though their experiences as coaches and an opportunity to comment on anything that they felt was important to their experience but was not covered previously.

\section{Data Analysis}

Upon reaching data saturation and completing the transcription process, member checks were performed to assure that the thoughts of the participants were properly represented and to allow the coaches the chance to add on information if they chose to do so. The primary researcher completed all of the coding of the data. MAXqda 
10 software was used for coding the interviews as it facilitates hierarchal coding and the grouping of open codes into categories and themes. An adaptation based on principles of Charmaz's (2006) constructivist grounded theory was chosen as a foundation as it places the emphasis on the participants and their meanings and experiences during the analysis process. The researcher read through the interviews for initial ideas that emerged. Subsequently, in-vivo open coding was used to illicit the primary codes, such as coaching clinics, college classes, watching other coaches, and working with multiple coaches. Axial coding then allowed the researcher to begin to connect codes together, including learning from others, coaching related education, and mentor relationships. Finally, selective coding resulted in the emergence of three themes regarding success strategies: leadership as athletes, education, and coaching connections as well as a theme of optimism toward their careers. These themes were chosen because the majority, at least half, of the coaches discussed each of these three themes.

To assure intercoder reliability, an outside researcher, unfamiliar with the data, independently coded $10 \%$ of the data. This coder was asked to code the same passages as the primary researcher and the selection was compared for agreement with the primary researcher. Eighty percent agreement is recommended (Creswell, 2007); the primary researcher and the independent coder had $89 \%$ agreement between passages. To assure intracoder reliability, the first author recoded $10 \%$ of the data approximately two years after the initial coding. The same codes emerged from the data.

\section{Findings and Discussion}

Given the phallocratic structure of intercollegiate coaching professions in the 21st century, the few women who do enter the coaching profession in pursuit of head coaching positions constantly face hurdles to their success. Millennials bring different experiences and backgrounds to the workplace compared with previous generations, including being more optimistic about life outcomes, technologically savvy, and their increased exposure to collaborative learning and team sports has made them take more of a team and collaborative approach to life and work (Howe \& Strauss, 2000). This optimism, exposure to collaborative learning and experience in sport may affect how millennials handle the hurdles they face during their careers. Hence, given the increased presence of millennials in the workforce, the purpose of this study was to investigate what factors influenced millennial generation, female assistant coaches' aspirations to become head coaches and what strategies they believed would help them successfully navigate their careers.

Similar to Leberman and Palmer's (2009) findings that mothers in sport leadership positions had a passion for sport and an ambition that helped them negotiate their dual roles, the assistant coaches in this study had a collective sense of positivity and passion for their sport which drives their careers and helps them believe that they could succeed in the coaching world. Further, the participants had an overall positive outlook on their careers, believing that they could become head coaches and that it was a good time to be a female coach. The assistant coaches in this study also talked about their experiences as leaders as athletes and the human and educational resources that they had access to and how those resources help them to 
get ahead. Moreover, previous research has identified developmental programs and coaching education (Borland \& Bruening, 2010; Sagas et al., 2006) as strategies to help women enter and stay in coaching; but, the participants in this study had a significantly different view on the usefulness of coaching education than previous studies discussed. These four main themes-optimism, leadership, education, and coaching connections-suggest a formula for success for female coaches (see Figure 1) which sport administrators and coaches can use to improve their tactics for preparing women for success as coaches. By focusing on strategies developed from millennial generation female coaches, these strategies are sensitive to the needs of the new generation of coaches based on the human, social, and cultural capital they bring to the profession.

Four dominant themes emerged in regards to what strategies helped the assistant coaches in this study to succeed and what they thought would help them reach their career goals. Optimism, leadership as athletes, education, and learning from other coaches were primary strategies that the assistant coaches saw as being beneficial to their career advancement. These strategies come from the standpoint of millennial coaches who are embedded in the gendered structure of coaching. As such, some of these strategies are unique to their generation and critique the practices currently employed by the sport organizations and administrators.

\section{Optimism Toward Coaching Careers}

Millennials are unlike previous youth generations that entered the workforce, as they tend to be better educated, and to have a more optimistic outlook on life (Howe $\&$ Strauss, 2000). In accordance, the women interviewed for this study were very optimistic about their careers and their ability to become head coaches. Optimism emerged from the data as an overarching theme because seven of the ten coaches explicitly wanted to become collegiate head coaches in their respective sports and all believed that this was an attainable goal with few perceived barriers. They were optimistic about their careers and the current state of women in coaching. Of the three coaches who did not have head coaching aspirations, one was a young coach unsure of her career plans, one was the novice coach in her rowing program and wanted to stay as a novice coach, and one wanted to leave collegiate coaching all together to become a high school teacher and coach.

This heightened optimistic outlook of women in sport is likely attributed to their experience as millennials. Although many females in this generation do not openly identify as feminists, the society they grew up in, that feminists in previous generations helped create, has instilled in them confidence, a desire for equality, and a more liberal outlook (Abowitz, 2008; Marcotte, 2013). They are beneficiaries of feminist movements, changes in prevalent gender ideologies and civil rights laws

\section{Positive Outlook + Athletic Leadership + Applied Education + Coaching Connections}

Success in Coaching Attainment

Figure 1 -Formula for Success for Female Coaches 
such as the Civil Rights Act and Title IX that focused on equality and opportunity in sport and the larger society. Hence they faced fewer barriers to participation or employment than many previous women have faced. The assistant coaches approached their careers with a belief that life would work out however it was meant to, which allowed them to deal with some of the challenges they faced in their careers without dwelling on them. Emily, a rowing coach, said, "I would say for me personally, just like a lot of women, it's just trying to figure out how you're going to do it all." Even though they admitted to struggling with the question of how to balance achieving it all—partner, kids, and a head coaching position-they approached their career with the idea that life would work out. Katie (soccer) said, "I feel like you can always get around problems." This sentiment was echoed by all seven of the assistant coaches that planned on pursing collegiate head coaching careers and helped give the participants positive attitudes regarding their futures.

This positive attitude about their futures was influenced by their perceptions that it was a good time for women in coaching despite negative employment trends. Five of the participants believed that competent female coaches were well positioned as athletic departments wanted to have more women on the staff of their women's teams. Robin (soccer), who had nine years of experience at several universities, described this view:

I think females...we do have a little bit of a jump over the males in our profession because so many programs want female coaches. And whether they want female head coaches or whether a head coach needs a female on staff, I definitely think we get, a good female coach gets, a lot more opportunities than a good male coach just because of gender equity.

Similarly, Claire stated that "I think there's more opportunity for women if you are a good coach. I think universities like to look for female coaches for female teams." Kim (rowing) and Emily (rowing), however, were both aware of, and concerned about, the attrition of female coaches. Kim, who planned to pursue a career as a head coach, was very positive about the state of women in sports, but was cognizant of attrition rates: "But even I have a bit of a negative outlook on it because I see the women who are having babies and they take a step back and the things do get a little less competitive." However, even while concerned about the number of female coaches who were leaving the profession, the women were optimistic about their careers and the field in general. This optimism shows that they were not allowing actual and perceived barriers to negatively deter them from pursuing head coaching positions. As such, the participants' optimism may be serving as a buffer from selflimiting behaviors. Feminists highlight that women need this increased optimistic outlook when faced with unfavorable environmental factors-in this case the low representation of women, structural barriers, and gendered coaching preferences.

\section{Leadership as Athletes}

In addition to having an optimistic outlook, the participants talked about the importance of leadership roles as athletes. They believed that their positions as captains and coxswains on their teams allowed them to learn leadership skills that transfer to coaching. As team leaders they had to be assertive and believe in their abilities 
as athletes and as leaders. As a result, in contrast to research that suggests female coaches have low coaching efficacy (Barber, 1998; Cunningham et al., 2003), the women that participated in this study have increased self-efficacy through practicing leadership as athletes and have the knowledge and ability to lead a group of athletes. The assistant coaches discussed how their varsity athletic experience and time in leadership positions as athletes helped their coaching careers. For example, four participants described how simply being strong athletes helped them to be recognized by other coaches as they transitioned into coaching. Claire (soccer) said,

I think just being a good player. I think coaches knew who I was when I played and if you're somewhat good then they kinda more respect you. This had effect, just because I am so young, I think that was my biggest plus when I started applying.

Katie (soccer) talked about how being a strong player from a good team helped in attaining coaching jobs and moving up within the field,

I think a lot of people talk about where you played and what level you played and there definitely are some great coaches out there who didn't play at a high level but playing at a high level just allows you to be recognized more or to be given more opportunities [...] I think that it's probably one of the biggest things in coaching that gives you a little bit of street cred I guess.

While they all had collegiate playing experience, five of the participants discussed how their leadership positions when they were athletes helped them transition from player to coach. As captains, coxswains, and point guards on their respective teams they had to develop strong leadership, coaching, and interpersonal skills. Two of the rowing coaches discussed their time as coxswains and how they were the coach on the water for their boat which taught them the rudimentary elements of working with athletes. Nicole (rowing) described this:

I rowed in high school but in college I was a coxswain and coxswain are essentially, they kinda are a coach when a coach isn't there. We have a really big leadership role, we kinda have to take charge of the team, we have to make some decisions. We have to be able to correct the girls. If the coach isn't there, we have to be able to say 'you need to do this, do that' so I kind of had a bridge into coaching because of cox'ing which has helped give me more confidence starting out as a new coach.

The assistant coaches viewed their time as athletes, particularly time spent as leaders on their teams, as important to their coaching careers. As millennials, they had more opportunities to be leaders as athletes than previous generations. They believed that their leadership positions gave them credibility to other coaches, including three who were hired by a coach they had competed for as athletes. As strong athletes and leaders on their teams, they gained knowledge of leading a team and increased their visibility to programs where they would work in the future. Therefore, as suggested by Lirgg et al. (1994) and Lough (2001), coaches should begin mentoring future coaches while they are still players, so as to increase their self-efficacy and leadership traits before they enter the male dominated coaching world. 


\section{Role of Education}

A third prominent theme that emerged from the data was ineffectual coaching education. Some have suggested that increasing women's opportunity for coaching education could help women enter and stay in coaching (Sagas et al., 2006); but, the women in this study did not see the traditional coaching clinics as useful to them unless they placed heavy importance on networking and mentoring-especially with other female coaches. Specifically, while eight of the participants had attended formal coaching clinics or held coaching certificates, the majority of the assistant coaches claimed that these clinics had limited utility. Three of them (one who had yet to attend any clinics) believed they could pick up a few tips about coaching at the coaching classes and clinics; whereas, the rest viewed them simply as a way to build their resumes and enhance their networks, rather than as tool to improve their actual coaching. Robin (soccer) stated that,

I have the highest license in the NSCAA, and then there are conventions every year, courses you can attend multiple times a year[...] I would say they are all basic for resume building. It's good for networking as well; you get to meet a lot of people in the profession. The early courses, when you're young, I think they help; but once you get older and into the upper classes, no, I think purely you need for your resume, you need for your job and you need to just have. You're not really getting anything out of it.

Rachel (rowing) likewise opined that there was only a little to be gained from coaching education. She asserted, "I think a lot of the coaching conferences and classes are kind of elementary a little bit, but I think you can always pick up on some of that stuff." These women have had more experience playing the sports at very high levels and playing under multiple coaches, causing some of the tactical and sport skill focuses of the clinics to be seen as rudimentary. Previous generations of female coaches may not have entered their careers with the same levels of sport knowledge of as these women; and thus, may have sought more of this type of information. Thus, due to the experiences and opportunities available to millennial women, the current structure of clinics is not seen as useful to the women beyond as a resume builder and networking tool.

College Education. Feminist social movements in the 20th century focused on the importance of education for liberation and empowerment; and played a significant role in the number of women and men entering universities. Accordingly, compared with previous generations, millennials are on track to being the best educated generation in U.S. history (Howe \& Strauss, 2000). In line with this educational trend, the participants all had college degrees and had attended at least one coaching specific educational clinic. They talked about how they applied knowledge acquired from coaching classes and certifications for their sport, as well as their undergraduate and graduate programs, to their careers. While these women did not find the coaching classes to be very informative, the majority of the coaches discussed how their college education, whether it was specific courses or an overall degree, was more useful in coaching.

Specifically, seven of the assistant coaches talked about how aspects of their college and graduate degrees were beneficial to their coaching careers. Blair 
(rowing), a music education major, found that her degree helped her as she saw coaching similar to teaching and could apply many of the strategies taught in her education classes:

I would say in my music education classes I learned a lot about those kinds of formal types or ways of teaching and learning styles and things like that. It seems like its left field with the music part of it, but in the end you're still getting someone to work and enjoy it, enjoy what they're producing and all that with a group. So it's actually very similar.

Laura (soccer) similarly applied what she learned as an exercise physiology major to her approach to coaching:

You know a large part of the game of soccer, and any sport for that matter, is fitness and you know I've been able to apply my knowledge in that, especially the different aerobic systems your body uses, energy systems. So I've been able to apply that in running fitness programs in the off-season for our athletes and during the season. So they've certainly been of use to me.

Possibly due to their high knowledge and experience of the sport, the millennial women in this study found their scholarly education, rather than their coaching education, to be more useful. The participants perceived education and kinesiology courses to be particularly useful in transferring the knowledge learned to their coaching careers; but believed certification clinics were mostly useful as networking opportunities as the clinics were too elementary.

\section{Coaching Connections}

Focusing clinics on social capital also addresses the women's discussion of networking and mentoring. They all had mentors, but desired stronger networks with other female coaches and administrators. They discussed how having a female mentor who they can turn to when facing challenges, such as balancing child rearing expectations with work, is extremely useful in navigating their careers. Millennials grew up in a culture that was more female friendly and accepting of women in equal positions in society, this taught them more collectivist and team oriented ways of thinking (Marcotte, 2013) and away from the individualistic approach that persons from older generations tend to have. Accordingly, the assistant coaches repeatedly discussed the importance of learning from other coaches to gain knowledge of coaching styles and how to run a program as well as the importance of learning from other female coaches how to navigate the gendered aspects of the field. The majority $(n=8)$ of the assistant coaches, from all three sports, discussed how important it was to change programs as they advanced their career. The assistant coaches understood that climbing the job ladder required moving to new programs. They saw this as a way to learn new styles and techniques from other coaches and to enhance their knowledge and networks. To advance, Rachel (rowing) believed that:

I would have to go to many other programs and be an assistant coach because I'm the second assistant - I coach the freshman - the next step would probably 
to be first assistant coach. And go to many different programs, that way I could learn from other coaches, other head coaches, other assistant coaches, before I felt comfortable taking over a program.

Robin (soccer) talked about what she learned by working at different programs with different coaches:

I think I took a lot from my college coaches and I take a lot from you know my boss that I'm with now as well so I also have learned from the previous schools I've been at. You're not always necessarily learning what to do; you are also learning what not to do.

The rowing coaches had another unique way to learn from other coaches that they looked up to, but did not work for. Three of the rowing coaches discussed how, at events, they watched the boats of other coaches. According to Kim (rowing):

The best informal education that I get is when I get to ride the launch of a coach I admire or a very successful coach. You know, I'll definitely go out to one of their practices and just kind of listen to how they say things, how they phrase things, or how they run practice all of that.

Rachel (rowing) echoed that sentiment, "It's great to even be able to, when you go and race another program to go and ride the launch of another coach and listen to them coach just kind of absorb how they do things." These assistant coaches found that learning from various other coaches was important. They did this primarily through watching other coaches at events and through moving programs every few years.

Mentor Relationships. Beyond learning from multiple coaches, the participants believed that having a couple of strong mentor relationships was extremely important. All of the assistant coaches had mentors who they saw as important to their coaching careers and to learning and progressing as coaches. Some of the mentors had been their coaches when they were athletes, while others were coaches that they had worked with or were currently working with. There was a general feeling that having somebody who they could call about problems or ask questions about coaching and life was extremely important to the coaches. For example, Blair (rowing) talked about her novice coach being a mentor, but also the desire for more mentoring opportunities:

My novice coach, I had a couple novice coaches, but one of them became a mentor and a co-worker at times and a pretty good friend [...] I still call my novice coach from way back when, but I would like more time to be mentored. We are actually changing our schedules around a little bit so that I can actually mentor with my bosses who are the head coaches, because currently my practices have been at the same time. We're a little bit tinned in here with time blocks, but I'm trying to make that happen.

While Blair was trying to form a stronger relationship with her current head coach, Laura (soccer) discussed how the head coach at her current school saw it as part of his job to mentor and prepare his assistants to advance in coaching. Even though 
she planned on leaving collegiate coaching, she appreciated this view and saw how it has set up many of his previous assistants for successful head coaching careers:

I'm very fortunate, where my boss is, he feels as if it's part of his job as a head coach to get his assistant coaches the experience necessary to become a head coach if that's what they want. So he does on a regular basis ask 'what can I do for you, I know you've been doing this, this, and this, $\mathrm{x}, \mathrm{y}$, and $\mathrm{z}$; do you want to try to do $\mathrm{a}, \mathrm{b}$, and $\mathrm{c}$ to get some experience doing those things to help make you more well-rounded in case you want to be a head coach'.

These assistant coaches have found great value from the mentoring they have received from current and past coaches as it pertained to learning coaching skills, and all of the assistant coaches had these types of relationships and believed they contributed to their success.

In addition, four of the coaches talked about the value of having female coaches as mentors and how these women could teach them not just about working with athletes, but also about how to navigate the field as female coaches. Katie (soccer) mentioned the first coach she worked with during an internship:

I had the lady that I did my internship under, who was my strength coach my last two years in college, she was one of my big mentors. She just taught me a lot about life, and you know, being a female, being a coach, stuff like that has stuck with me in being a coach.

Claire (soccer) expanded on this idea and talked about how it was her female college coach who allowed her to view coaching as a career option and that it was possible to 'do it all.' This coach continued to serve as a mentor as Claire pursued her coaching career:

I played at University and I had a female coach who has been there now for like 14 seasons and she has a family and she's pretty much the reason I wanted to get into coaching. I saw that she was able to have a successful team and have a family as well so I know that that made me want to pursue my career [...] if I had a problem I know I could call her and she'd give me her opinion and she's one who, she always knew I wanted to do this and she's been helping me ever since I knew I wanted to.

As Claire exemplified with her relationship with her college coach, the assistant coaches valued mentors in teaching them about coaching and working with athletes but also about life, being a female coach, and showing them how to navigate the challenges that are present for female coaches. According to feminist standpoint theory, women experience the workplace, particularly male dominated work, differently from men, and their different social locations and experiences result in distinct situated knowledge. In light of this, the participants valued learning how other female coaches achieved work-life balance and having a connection with somebody who has had similar experiences to themselves.

Networks. While having strong mentors was very important for these assistant coaches' professional development, strong networks were also deemed important especially when it came to moving up in the field. Nine of the participants explicitly 
discussed the importance of networks. They believed that their experience as athletes, moving programs, and attending various coaching clinics and conferences, including women's only conferences, helped to build these networks that would help them get better jobs and allow them to achieve their career goals. Emily (rowing) exemplified all three of these aspects of networking in her description of how networking has helped her.

The one advantage that I think that I definitely have is that because I was a very successful international rower, just the relationships you create. I know a lot of people when we go to the US Rowing Conference. I know just about everybody so I'm a very social person; I think that that has helped me a lot and I know that that is what brought me some of the opportunities, the opportunity that I was presented with this summer, you know, a lot of it is just how you present yourself. It's not exactly formal, but I think that just because I was a student athlete you know, I've been lots of places so I think that has just naturally created networks.

Robin discussed how her networks have helped her get all of the coaching jobs she has held:

My very first job kinda just fell into my lap and I was only there for 6 months before I was hired by a Division I school. And then I was able to get my masters for free while being paid and then I had the opportunity to go back to [alma mater] as a volunteer and then an assistant. A year after I got hired there, that coach left and I came with him here. So I've never really gone after any of the jobs that I've been given, had to apply on line and do the resume or any of that stuff for any of these jobs.

Other coaches noted similar experiences and sentiments about the usefulness of networking. These networks have helped the assistant coaches get jobs and advance their careers and most of the assistant coaches reiterated the importance of networking in various ways as a key component to success in achieving their goals.

Three of the assistant coaches talked more specifically about networking with other women, opportunities to meet other female coaches at conferences, and how those networks were uniquely useful. They discussed women's specific developmental programs such as the Women's Coaches Academy, and the So You Want to be a Coach clinic. These programs allowed them to network and learn from other female coaches both about how to be better coaches as well as how to overcome the challenges that are common to women in the field. This reinforced Borland and Bruening's (2010) finding that targeted developmental programs are important for minority coaches. For example, Christine (women's basketball), who started pursuing coaching after her college coach suggested she attend a clinic called "So You Want to be a Coach" which grooms minority athletes to become coaches, said, "I've also been part of the Women's Coaches Academy. Just women, strong networks, and that has just been great." Meanwhile Emily (rowing) was looking forward to gaining this unique networking opportunity as she had seen the benefits it had for her coworkers:

Next summer I'm going to the NCAA Female Leadership Academy, so I'm doing that [...] It's about promoting women within athletics and I think part of 
it, I think part of the goal is to keep females, especially assistants in coaching, and to really promote females being involved in female athletics [...] I'm very good friends with our assistant water polo coach and she went and met the head rowing coach at [University] who just happened to be at the same one. So it just kinda creates networks.

While the assistant coaches did not always find the educational aspects of the clinics to be useful, they highly valued all of the networking and mentoring opportunities they received. The participants seemed to put a particular emphasis on the opportunities and knowledge that they could gain from connecting with other female coaches. They saw it as an opportunity to link up with other coaches who may have had similar experiences, issues and successes as they had encountered and as a chance to learn from their predecessors how to be successful and how to 'do it all." The coaches found networking with others who had similar experiences in the male dominated coaching world, to be a useful strategy in pursuing a career as a head coach. Kim (rowing) described her appreciation of the cohesiveness of these women's only networks,

I think my generation of peers, where a lot of us are assistant coaches all the same age, and as we are struggling through and try to develop our careers and what not, I think it's very positive to have that peer structure. Yeah, I think it's positive and I'm excited for the sport of rowing and for female coaches.

These opportunities not only help the women individually but also can help to create an old girl's club that previous studies have found to be absent from the field (Bracken, 2009; Coakley \& Donnelly, 2009; Cunningham \& Sagas, 2003). Female mentors also help with navigating the male dominated field. These mentors not only helped female assistant coaches gain knowledge of the sport and of coaching, but also about how to be a successful female in the field. The mentors showed them that it was possible to "do it all" - to be a successful coach, spouse, and parent. The participants in this study looked up to their female mentors to learn about coaching, and to learn about what it is like to be a female in a male dominated field. This supported Avery et al.'s (2008) finding that same-sex mentor pairings led to higher levels of career development than opposite-sex mentor pairings. Previous literature has pointed to organizations starting mentoring programs specifically for female assistant coaches (Bloom et al., 1998; Weiss et al., 1991).

\section{Conclusions}

Women's experiences and opportunities in sport are inherently different from men due to cultural and social gendered ideologies and expectations in conjunction with their lowered status and positions of power. Likewise, women's experiences differ from each other due to different generational and cultural experiences and different opportunities in society. Thus, feminist standpoint theory helps to situate the knowledge gained from this study as unique to millennial women due to their past and current experiences in athletics and society. By directly asking millennial generation, female, assistant coaches, this study was able to gain insight into their situated experiences and to understand how their experiences and history may give 
this generation a new perspective on the occupation and the coaching institution from previous generations. Due to men's positions of power within the athletic structure, men would view barriers to coaching and their roles within the organizations differently. Therefore, the generation of knowledge from the standpoint of women who are navigating the complexities of this gendered structure allows knowledge that can be empowering for both women currently employed as coaches and future women entering the profession.

The findings show that the experiences of this group of women are unique and sociohistorically situated. For instance, despite negative trends in the hiring of female coaches, the women in this study were very positive and optimistic about their careers as assistant and potentially head coaches. This positive psychological capital (i.e., high self-efficacy, optimism, hope and resiliency) is characteristic of millennials, and can actually help them succeed in life. As noted by Mahatma Gandhi:

Man [sic] often becomes what he [sic] believes himself [sic] to be. If I keep on saying to myself that I cannot do a certain thing, it is possible that I may end by really becoming incapable of doing it. On the contrary, if I have the belief that I can do it, I shall surely acquire the capacity to do it even if I may not have it at the beginning.

Thus, given that optimism is a natural trait and a learned skill (Seligman, 2006), women need to develop and/or maintain a sense of hopefulness, confidence and positivity about their career. Moreover, to support positive optimism, discourses of women's negative experiences in sport need to be balanced with rhetoric of hope.

This study's findings also underline the need for a critical evaluation of the current programming of coaching clinics. They are often highlighted as a way to help support female coaches; however, as aforementioned, the women in this study saw them as basic and elementary, only useful for networking. The participants found their college courses on teaching and exercise science to be applicable and sufficient to coaching, and hence, were not lacking requisite sport knowledge and tactical skills to coach their sport. In contrast to the previous generations, this generation of women grew up playing sports at the highest levels, learning from multiple coaches and are very familiar with the skills and tactics of the sport. Thus, instead of coaching support systems that emphasize correcting human capital deficiencies, there should be a focus on correcting social capital inequalities present in coaching positions, as the current focus of coaching clinics on increasing coaching aptitude may not be a useful mechanism in addressing the underrepresentation of women in coaching. These findings underpin the importance of gathering knowledge directly from the standpoint of the women who are navigating the confining, gendered structure.

Through the lens of feminist standpoint theory, altering the focus of the clinics would be taking situated knowledge of the female assistant coaches and use that knowledge to create an environment that better serves the needs of the current community. The clinics should be restructured either to focus more on exercise science and teaching theory, or in line with Lemyre, Trudel and Durand-Bush's (2007) suggestion that coaching education could be altered to foster a community of practice among coaches. This will allow the clinics to become meaningful for 
female coaches and potentially serve as settings that can help female coaches be successful in their careers. Organized coaching clinics may be able to serve as the structure to facilitate the creation of this community; and creating a community of practice through coaching education could encourage more networking and sharing of knowledge among female coaches. This may be especially useful for millennial generation female coaches as this generation already tends to be more oriented toward collectivistic leadership approaches, and many know each other from their time as athletes. As such, this community could facilitate a continued connection and knowledge sharing between these women. This will allow the clinics to become meaningful for female coaches and potentially serve as settings that can help female coaches be more successful in overcoming constraints in their careers.

Also, by listening to the situated knowledge of women, this focus on womenonly mentoring and networking should be taken to heart by coaches, sport organizations, and athletic departments to create more opportunities and settings for this to occur. For example, sport organizations could create mentorship programs for young coaches, with a focus on matching new female coaches with more experienced female coaches so that they can learn from their predecessors in the field. Thus, by listening to the emphasis that millennial generation female coaches have placed on the importance of women specific networking opportunities, sport organizations can change their practices to actually serve the coaches in ways that the women, rather than the male structure, find useful. It is important to note, that these women did not negate the importance of networks with men, they simply emphasized the unique importance of female connections. Having women's networks helps to increase their collective power and change the dynamic in the field, possibly helping women to avoid self-limiting behaviors because they have other women to help and support them. An "old girls club" would help to increase the social capital that female coaches are currently lacking and help them to navigate a male dominated field. It would help to combat the current male power and give women access to resources currently dominated by men.

\section{Limitations and Future Research}

This study's findings make an important contribution to knowledge that can help reverse the negative hiring trend for women in sport, but a few limitations of the study should be taken into account. First, telephone interviews can allow for more information to be collected as interviewees check their answer for adequacy more frequently with telephone interviews and allow for more honest answers due to their comfort with virtual communication (Irvine, Drew, \& Sainsbury, 2013; TrierBieniek, 2012). However, while telephone interviews provide information when in-person access is not possible, they do not allow for the informal and nonverbal communication that takes place in person (Creswell, 2007; Irvine, Drew, \& Sainsbury, 2013); this could have limited the depth of information gained.

This study is also limited in that it only surveyed assistant coaches from three sports: basketball, soccer, and rowing. A broader group of sports should be investigated, particularly individual sports to see if those coaches have similar experiences. Further, while head coaches were outside of the scope of this study, future research should look at the perspectives of current married and single millennial generation head coaches, with and without children, to see what their experiences are in this 
endeavor. It would be useful to understand the strategies that they believe helped them to achieve success and balance their career aspirations and personal lives. Finally, women are not a monolithic group; and thus, other millennial women may not share the same optimism and attitudes toward coaching clinics as these women. For instance, coaches of color and lesbian coaches could have different experiences from white or heterosexual coaches, leading to different outlooks and perceptions of their career possibilities. The voices of a multitude of diverse millennial generation female coaches is important to extending the situated knowledge of millennial generation female assistant coaches; and can provide a feminist perspective for ways in which athletic organizations alter the resources provided for their coaches, particularly in ways that can help women navigate the hegemonically masculine structure.

\section{References}

Abowitz, D.A. (2008). The campus "F" work: Feminist self-identification (and not) among undergraduates. International Journal of Sociology of the Family, 34(1), 43-63.

Acosta, R.V., \& Carpenter, L.J. (2012). Women in intercollegiate sport: A longitudinal national study. Thirty-three year update (1977-2012). Retrieved January 23, 2012, from http://acostacarpenter.org/AcostaCarpenter2012.pdf.

Aitchison, C. C. (2005). Feminist and gender research in sport and leisure management: Understanding the social-cultural nexus of gender-power relations. Journal of Sport Management, 19(4), 422-441

Avery, D.R., Tonidandel, S., \& Phillips, M.K.G. (2008). Similarity on sports sidelines: How mentor-protégé sex similarity affects mentoring. Sex Roles, 58(1), 72-80. doi:10.1007/ s11199-007-9321-2

Barber, H. (1998). Examining gender differences in sources and levels of perceived competence in interscholastic coaches. The Sport Psychologist, 12(3), 237-252

Bianchi, S.M., Robinson, J.P., \& Milkie, M. (2006). Changing Rhythms of American Family Life. New York: Russell Sage Foundation.

Bloom, G.A., Durand-Bush, N., Schinke, R.J., \& Salmela, J.H. (1998). The importance of mentoring in the development of coaches and athletes. International Journal of Sport Psychology, 29, 267-281.

Borland, J.F., \& Bruening, J.E. (2010). Navigating barriers: A qualitative examination of the under-representation of black females as head coaches in collegiate basketball. Sport Management Review, 12(4), 407-420. doi:10.1016/j.smr.2010.05.002

Bower, G.G. (2010). Examining women's coaching desires; perspectives from assistant women's basketball division I coaches. The Indiana Journal for Health, Physical Education, Recreation. Dance, 39(3), 22-29.

Bracken, N. (2009). Perceived barriers: 2008-2009 gender equity in college coaching and administration: Perceived barriers report. National Collegiate Athletic Association.

Charmaz, K. (2006). Constructing Grounded Theory: A Practical Guide through Qualitative Analysis. Los Angeles, CA: Sage.

Claringbould, I., \& Knoppers, A. (2008). Doing and undoing gender in sport governance. Sex Roles, 58(1), 81-92. doi:10.1007/s11199-007-9351-9

Coakley, J.J., \& Donnelly, P. (2009). Sport in society: Issues and controversies. New York: McGraw-Hill.

Creswell, J.W. (2007). Qualitative inquiry \& research design: Choosing among five approaches. Los Angeles, CA: Sage Publications.

Cunningham, G.B., Doherty, A.J., \& Gregg, M.J. (2007). Using social cognitive career theory to understand head coaching intentions among assistant coaches of women's teams. Sex Roles, 56(3), 365-372. doi:10.1007/s11199-006-9175-z 
Cunningham, G.B., \& Sagas, M. (2003). Occupational turnover intent among assistant coaches of women's teams: The role of organizational work experiences. Sex Roles, 49(3), 185-190. doi:10.1023/A:1024469132536

Cunningham, G.B., Sagas, M., \& Ashley, F.B. (2003). Coaching self-efficacy, desire to become a head coach, and occupational turnover intent: Gender differences between NCAA assistant coaches of women's teams. International Journal of Sport Psychology, 34, 125-137.

Dixon, M.A., \& Bruening, J.E. (2007). Work-family conflict in coaching I: A top-down perspective. Journal of Sport Management, 21(3), 377-406.

Drago, R., Hennighausen, L., Rogers, J., Vescio, T., \& Stauffer, K.D. (2005). Final report for CAGE, the coaching and gender equity project. Department of Labor Studies and Industrial Relations, Pennsylvania State University.

Everhart, C.B., \& Chelladurai, P. (1998). Gender differences in preferences for coaching as an occupation: The role of self-efficacy, valence, and perceived barriers. Research Quarterly for Exercise and Sport, 69(2), 188-200. PubMed doi:10.1080/02701367.1 998.10607683

Granovetter, M.S. (1973). The strength of weak ties. American Journal of Sociology, 78, 1360-1380. doi:10.1086/225469

Harding, S. (1987). Feminism \& Methodology. Bloomington, IL: Indiana University Press.

Hartsock, N. (2004). The feminist standpoint: Developing the ground for a specifically feminist historical materialism. Discovering Reality, 161, 283-310. doi:10.1007/0306-48017-4_15

Howe, N., \& Strauss, W. (2000). Millennials Rising: The Next Great Generation. New York: Vintage.

Ibarra, H. (1993). Personal networks of women and minorities in management: A conceptual framework. Academy of Management Review, 18, 56-87.

Irvine, A., Drew, P., \& Sainsbury, R. (2013). Am I not answering your questions properly?' Clarification, adequacy, and responsiveness in semi-structured telephone and face-toface interviews. Qualitative Research, 13(1), 87-106. doi:10.1177/1468794112439086

Johnson, J.A., \& Johnson, M.S. (2008). New city domesticity and the tenacious second shift. Journal of Family Issues, 29(4), 487-515. doi:10.1177/0192513X07310313

Johns, G., \& Saks, A.M. (2004). Organizational Behaviour: Understanding and Managing Life at Work (6th ed.). Upper Saddle River, NJ: Prentice Hall.

Kamphoff, C.S. (2010). Bargaining with patriarchy: Former female coaches' experiences and their decision to leave collegiate coaching. Research Quarterly for Exercise and Sport, 81(3), 360-372. PubMed

Kane, M.J., \& Stangl, J.M. (1991). Employment patterns of female coaches in men's athletics: Tokenism and marginalization as reflections of occupational sex-segregation. Journal of Sport and Social Issues, 15(1), 21-41. doi:10.1177/019372359101500102

Krane, V. (2001). One lesbian feminist epistemology: Integrating feminist standpoint, queer theory, and feminist cultural studies. The Sport Psychologist, 15, 401-411.

Leberman, S., \& Palmer, F. (2009). Motherhood, sport leadership, and domain theory: experiences from New Zealand. Journal of Sport Management, 23(3), 305-334.

Lemyre, F., Trudel, P., \& Durand-Bush, N. (2007). How youth-sport coaches learn to coach. The Sport Psychologist, 21, 191-209.

Lirgg, C.D., DiBrezzo, R., \& Smith, A.N. (1994). Influence of gender of coach on perceptions of basketball and coaching self-efficacy and aspirations of high school female basketball players. Women in Sport and Physical Activity Journal, 3(1), 1-15.

Lough, N.L. (2001). Mentoring connections between coaches and female athletes. Journal of Physical Education, Recreation \& Dance, 72(5), 30-33. doi:10.1080/07303084.2 001.10605749

Lowry, C.D., \& Lovett, D.J. (1997). Women coaches: Does when dictate why they leave? Applied Research in Coaching and Athletics Annual, 12, 35-53. 
Marback, T.L., Short, S.E., Short, M.W., \& Sullivan, P.J. (2005). Coaching confidence: An exploratory investigation of sources and gender differences. Journal of Sport Behavior, $28(1), 18-35$.

Marcotte, A. (2013). The wanted generation. Retrieved from http://www.thedailybeast. $\mathrm{com} /$ witw/articles/2013/05/22/thank-feminism-for-millennials-cooperative-liberalspirit.html.

Pastore, D.L. (1991). Male and female coaches of women's athletic teams: Reasons for entering and leaving the profession. Journal of Sport Management, 5, 128-143.

Sagas, M., Cunningham, G.B., \& Pastore, D. (2006). Predicting head coaching intentions of male and female assistant coaches: An application of the theory of planned behavior. Sex Roles, 54(9), 695-705. doi:10.1007/s11199-006-9035-x

Sagas, M., Cunningham, G. B., \& Teed, K. (2006). Examining homologous reproduction in the representation of assistant coaches of women's teams. Sex Roles, 55, 503-510.

Seibert, S., Kraimer, M., \& Liden, R. (2001). A social capital theory of career success. Academy of Management Journal, 44, 219-237. doi:10.2307/3069452

Seidman, I. (2006). Interviewing as Qualitative Research. New York: Teachers College Press.

Seligman, M.E. (2006). Learned Optimism: How to Change Your Mind and Your Life. New York: Vintage.

Shaw, S., \& Frisby, W. (2006). Can gender equity be more equitable?: Promoting an alternative frame for sport management research, education, and practice. Journal of Sport Management, 20(4), 483-509.

Stangl, J.M., \& Kane, M.J. (1991). Structural variables that offer explanatory power for the underrepresentation of women coaches since Title IX: The case of homologous reproduction. Sociology of Sport Journal, 8(1), 47-60.

Stake, R.E. (1995). The Art of Case Study Research. Thousand Oaks, CA: Sage Publications. Taylor, P., \& Keeter, S. (2010). Millennial: A Portrait of Generation Next: Confident, Connected, Open to Change, 24 Feb. Washington, DC: Pew Research Center.

Title, I.X. Education Amendments of 1972, 20 U.S.C. $§ 1681$ et seq. (United States Department of Labor).

Trier-Bieniek, A. (2012). Framing the telephone interview as a participant-centered tool for qualitative research: a methodological discussion. Qualitative Research, 12(6), 630-644. doi:10.1177/1468794112439005

Weiss, M.R., Barber, H., Sisley, B.L., \& Ebbeck, V. (1991). Developing competence and confidence in novice female coaches: II. Perceptions of ability and affective experiences following a season long coaching internship. Journal of Sport \& Exercise Psychology, 13, 336-363.

Weiss, M.R., \& Stevens, C. (1993). Motivation and attrition of female coaches: An application of social exchange theory. The Sport Psychologist, 7, 244-244.

Welch, S., \& Sigelman, L. (2007). Who's calling the shots? Women coaches in division I women's sports. Social Science Quarterly, 88(5), 1415-1434. doi:10.1111/j.15406237.2007.00509.x 